\title{
Assessment of Inferior Pedicle Technique for Large and Ptotic Breasts
}

\author{
AHMED H. ELSABBAGH, M.D. and AHMED E. ZAYED, M.Sc. \\ The Department of Plastic Surgery, Faculty of Medicine, Mansoura University
}

\begin{abstract}
Background: Reduction mammoplasty is one of the most commonly performed procedures in plastic surgery. Women who performed breast reduction gains relief of the symptoms associated with mammary hypertrophy and obtain good body image. The inferior pedicle Wise pattern reduction is the most common breast reduction technique. The new breast is made by stretching the skin over the parenchyma.
\end{abstract}

Objective: Assessment of inferior pedicle technique was made after management large ptotic breasts.

Patients and Methods: Between June 2012 and March 2017, a total of 21 patients with bilateral large ptotic breasts underwent inferior pedicle technique. Preoperatively, we measured for each patient her height, weight and body mass index (BMI) also the sternal notch-to-nipple distance.

Results: The mean age of the participants was 28 years (range: $22-45$ ). Average height was $155.2 \mathrm{~cm}$, average weight was $66.4 \mathrm{~kg}$ and the average BMI was $27.5 \mathrm{~kg} / \mathrm{m}^{2}$. In Egypt, women expressed bra size in numbers. The number size of bra decreased from 4-10 numbers down postoperatively (mean number: 6). These numbers were mainly subjective as many patients were not adequately evaluated for bra fitting. Reduction of up to $1500 \mathrm{~g}$ per side was achieved. The amount of tissue removed was between 800 and $1500 \mathrm{~g}$ per side in all patients (mean 950 gram). The mean surgical time was about 180 minutes.

Conclusion: Inferior pedicle technique with some technical refinements was proven to be an excellent technique for breast reduction of large and ptotic breasts.

Key Words: Breast reduction - Large ptotic breasts - Inferior pedicle technique.

\section{INTRODUCTION}

Reduction mammoplasty is one of the most commonly performed procedures in plastic surgery. The aim of any breast reduction is to reduce the volume of breast to fit the body without affection of its anatomy and its function. Breast reduction has been described in many series as having a high success rate and good patient satisfaction, specifically for those with macromastia [1-8].
There are several standard methods for reduction mammoplasty. The decision depends on the age of the patient, the degree of ptosis, the volume that needs to be excised, quality of skin, surgeon experience and patient expectation [9-11].

In 1669, Durston described a young woman (23 year) presented with enlarged breasts weighing $47.2 \mathrm{~kg}$. Unfortunately, the patient died immediately after mastectomy [12,13].

In general, a safer pedicle should be used in patients with severe breast hypertrophy and ptosis grade III in spite of the resulting longer scar. So, free nipple graft and inferior pedicle technique are highly recommended for large and ptotic breasts [14].

For over 70 years, free nipple areolar grafting has been used. It is indicated in the elderly high risk patients with comorbid diseases. In addition, it is indicated in women who had previous breast surgery or younger women with gigantomastia, or large ptotic breasts [15-18].

No doubt, the inferior pedicle Wise pattern reduction is the most common breast reduction technique. The newly formed breast is made by stretching the skin over the parenchyma [19-25]. Common complications are fat necrosis, infection and wound disruption. Most of these complications are minor and can be treated conservatively [26-29].

In this article, assessment of inferior pedicle technique was made after management large ptotic breasts.

\section{PATIENTS AND METHODS}

Between June 2012 and March 2017, a total of 21 patients with bilateral large ptotic breasts underwent inferior pedicle technique. Two patients had high blood pressure. None of our patients were smoker. 
Preoperatively, we had measured for every patient her height, weight and body mass index (BMI). Also the sternal notch-to-nipple distance, the vertical inframammary distance (the distance between the inferior border of the areola and the inframammary fold) and the horizontal distance between the sternal midline and breast meridian were measured.

Nipple sensation was assessed at nipple and at four points on the areola at 12,3,6, and 9 o'clock. Pressure thresholds were measured by Semmes Weinstein monofilaments. The area was considered insensate if pressure of monofilament (6.65) was not sensed.

Patients were admitted on the day of surgery and marked one hour before operation in the standing position. Informed consent was obtained from all patients involved in the study. Separate consent for photography was taken from all patients.

\section{Technique:}

Nipple location:

The nipple position was made in the meridian of the breast. Usually, the meridian could be drawn through the existing nipple position. Sometimes, the nipple could be too medial or too lateral to the site of the nipple. The position of nipples was put at the level of inframammary fold.

\section{Marking of medial and lateral limbs:}

By adopting Dr. Lejour method, the breast was rotated upward and inward to mark the lateral limb and then upward and outward to mark the medial limb. These lines would correspond to the vertical lines. These lines were measured $10 \mathrm{~cm}$ in length. The end of medial limb was marked $1 \mathrm{~cm}$ from the sternum. The end of lateral limb was at the end of the breast laterally.

\section{Tumescence:}

The breast was infiltrated with tumescent technique with adrenaline at concentration of 1/200.000. The infiltration was deep in all breast quadrants except the pedicle. The pedicle was infiltrated subdermally only to facilitate deepithelization.

\section{Inferior pedicle:}

The pedicle was at least $10 \mathrm{~cm}$ in width. It was designed in a pyramidal fashion with the base inferiorly directed. The pedicle was de-epithelialized leaving a $2 \mathrm{~cm}$ margin around the areola (Fig. 1). The pedicle was taken down to the pectoral fascia. It was important not to injure the fascia of pectoralis major muscle for two reasons (Fig. 2). The first one was to preserve sensation that came from the lateral side. The second one was to prevent seroma and hematoma formation that may result from injury to the muscle.

\section{Breast reduction:}

Before removal of the skin, the edges of the limbs were de epithelialized for $1 \mathrm{~cm}$ (Fig. 3). By this maneuver, the skin edges would not retract and could hold the sutures with less skin necrosis and dehiscence of the edges might occur. The skin and breast tissue were removed together. The breast tissue was removed very conservatively on the medial side to maintain fullness of the breast. The main resection was on the bulk of pedicle. Resection was made in a slicing manner aiming for closure of the breast without tension (Fig. 4). The lateral skin flap wad undermined extensively to allow closure of breast without tension. A thickness of $2 \mathrm{~cm}$ was sufficient to maintain vascularity of the lateral skin flap. Little breast tissue was removed superiorly to maintain upper pole fullness.

\section{Placement of the Nipple areola complex:}

The dog ear of the upper end of the vertical limb was the target. A circular opening of $5 \mathrm{~cm}$ in diameter was centered over the dog ear. The area was excised till the appearance of subcutaneous tissue. The nipple areola complex was delivered into the opening after marking of its corners with sutures. This would prevent distortion or kinking of nipple areola complex during delivery. The protrusion of nipple will be made by the weight of the inferior pedicle. No need to deepithelialize the opening. Deepithelialization made the delivery difficult and may constrict the pedicle and impair its blood supply.

\section{Closure of the areola:}

The areola was closed at three layers. The first layer was closed with $3 / 0$ vicryl at the subdermal level at 12, 3, 6 and 9 clock positions. Then, the areola was closed with 4/0 vicryl (interrupted subcuticular sutures). The skin was closed with interrupted $6 / 0$ proline sutures. Interrupted sutures are life boat for saving the areola. If there was any doubt in vascularity, Removal of one or two stiches will relief the tension without the need to reenter the operating theatre again.

\section{Closure of limbs:}

The sutures were used in a descending manner from below upwards. Subdermal sutures were taken by zero vicryl in interrupted fashion. Running subcuticular sutures were made by $3 / 0$ vicryl. Skin 
was closed by interrupted sutures using $5 / 0$ proline sutures.

\section{Drains:}

Drains were mandatory. For each breast, two drains were inserted. One placed below the pedicle and the other sited in front of it. The superficial one is very important as a healthy deepithelialized pedicle might collect a big hematoma that might make tension on the vertical limb with possibility of its disruption.

\section{Antibiotics:}

Third generation cephalosporin was used for 8 days. The first three days were taken parenterally.

\section{Garments:}

Compression garments were used for 4 successive weeks. The pressure garments were changed every week to maintain pressure.

\section{Postoperative care:}

Intact sensation of nipple ensures good vascularity of the nipple but not the reverse. Sutures were removed after 14 days.

\section{RESULTS}

The mean age of the participants was 28 years (range: 22-45). Average height was $155.2 \mathrm{~cm}$, average weight was $66.4 \mathrm{~kg}$ and the average BMI was $27.5 \mathrm{~kg} / \mathrm{m}^{2}$. In Egypt, women expressed bra size in numbers. The number size of bra decreased from 4-10 numbers down postoperatively (mean number: 6). Actually, these numbers were mainly subjective as many patients were not adequately evaluated for bra fitting.

Reduction of up to $1500 \mathrm{~g}$ per side was achieved. The amount of tissue removed was between 800 and $1500 \mathrm{~g}$ per side in all patients (mean 950 gram). The mean surgical time was about 180 minutes. Blood transfusion was not given in all cases. Drains were removed after three days. Length of hospital stay varied from one day postoperative to 3 days postoperative. Protrusions of sutures were noted in $25 \%$ of cases. Hypertrophic scar occurred in three dark pigmented skin cases.

No hematoma or seroma was encountered. Minor infection occurred in one case. Infection was confined to the skin and was treated conservatively. Minor disruption occurs at the inferior pole of nipple areola complex in two cases and at
T shaped junction in three cases. All were treated with conventional dressing. One case showed epidermolysis of nipple areola complex on the right breast. Healing was good with slight hypopigmentation of nipple areola complex (Fig. 7).

The horizontal distance between sternal line and breast meridian increased from 0.9 to $1.7 \mathrm{~cm}$ postoperatively. Intraoperatively, the vertical inframammary distance was about $6 \mathrm{~cm}$ and was increased to $7.5 \mathrm{~cm}$ at 6 months follow-up.

Complaints before surgery were significantly reduced. Also, intertrigo and unpleasant odors were significantly ameliorated. Breast pain, neck pain, shoulder pain and back pain were reduced significantly after operation.

Problems with clothing and external appearance before surgery were dramatically improved after surgery except for patients with short stature (3 cases). Data was taken from clinical notes. Body mass index values were measured before surgery. They did not show any significant difference or fall into normal values except in $25 \%$ of cases.

Nipple sensation was measured 3 weeks postoperatively. Most of patients experienced good nipple-areolar sensation postoperatively. Only 3 patients complained of a reduction in sensation unilaterally. It was observed to occur in the side with more excision.

Symmetry was achieved in most cases (19 cases). The distance between the jugular notch and the nipple showed a difference between the two sides of $7 \mathrm{~mm}$ or less. The horizontal distance between sternal line and breast meridian increased from 0.9 to $1.7 \mathrm{~cm}$ postoperatively. The submammary folds showed a difference of $5 \mathrm{~mm}$ or less. Intraoperatively, the vertical inframammary distance was about $6 \mathrm{~cm}$ and was increased to $7.5 \mathrm{~cm}$ at 6 months follow-up. In two women, the distance between the jugular notch and the nipple showed a difference of $1-1.5 \mathrm{~cm}$. Also, the submammary folds showed a difference of $1.5-2 \mathrm{~cm}$. There was correlation between breast size and the difference between two breast size and asymmetry (Fig. 8).

The inframammary folds were at the same level in 19 women and 2 women had a median difference of $1 \mathrm{~cm}$. No dog ear or symmastia was encountered. Neither reoperation nor seeking for $2^{\text {nd }}$ opinion was requested by any patient in this study. The follow-up period extended up to 6 months. 


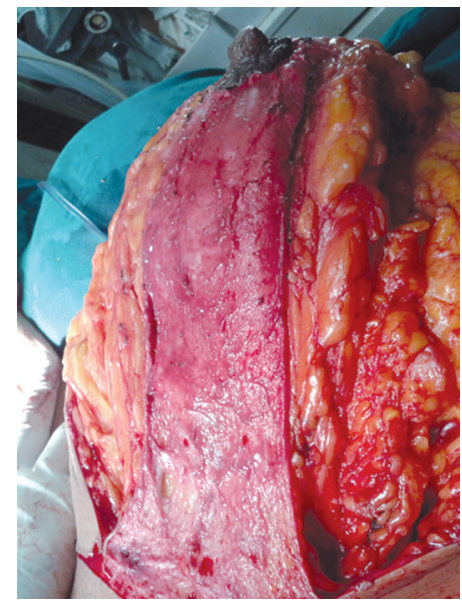

Fig. (1): Deepithelization of the inferior pedicle.

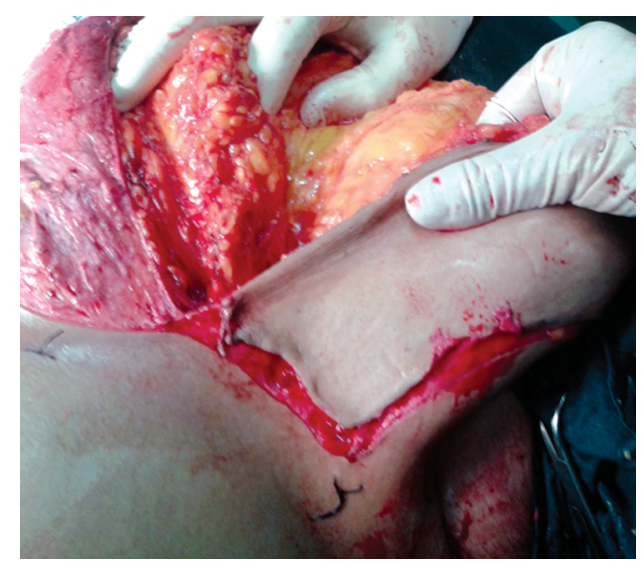

Fig. (3): Deepithelialization of skin flaps.

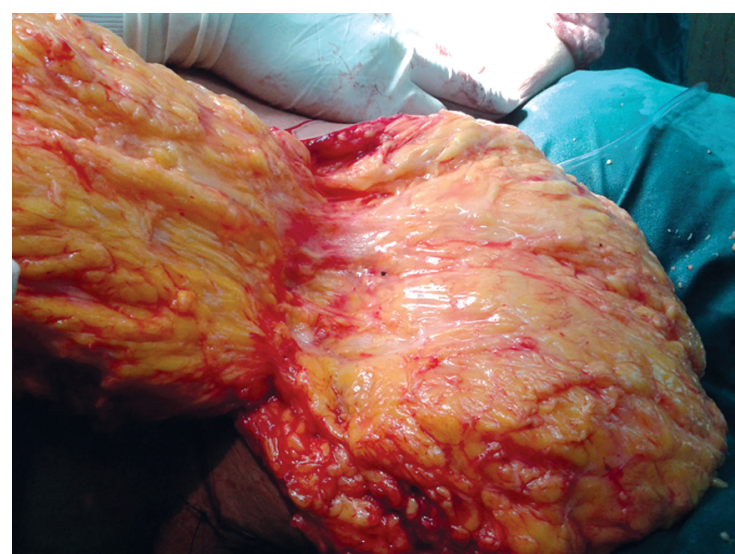

Fig. (2): Dissection of the pedicle down to pectoralis fascia.

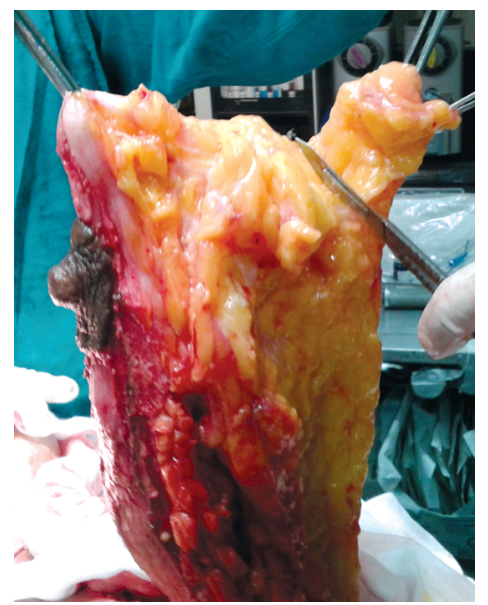

Fig. (4): Slicing and contouring of the inferior pedicle.
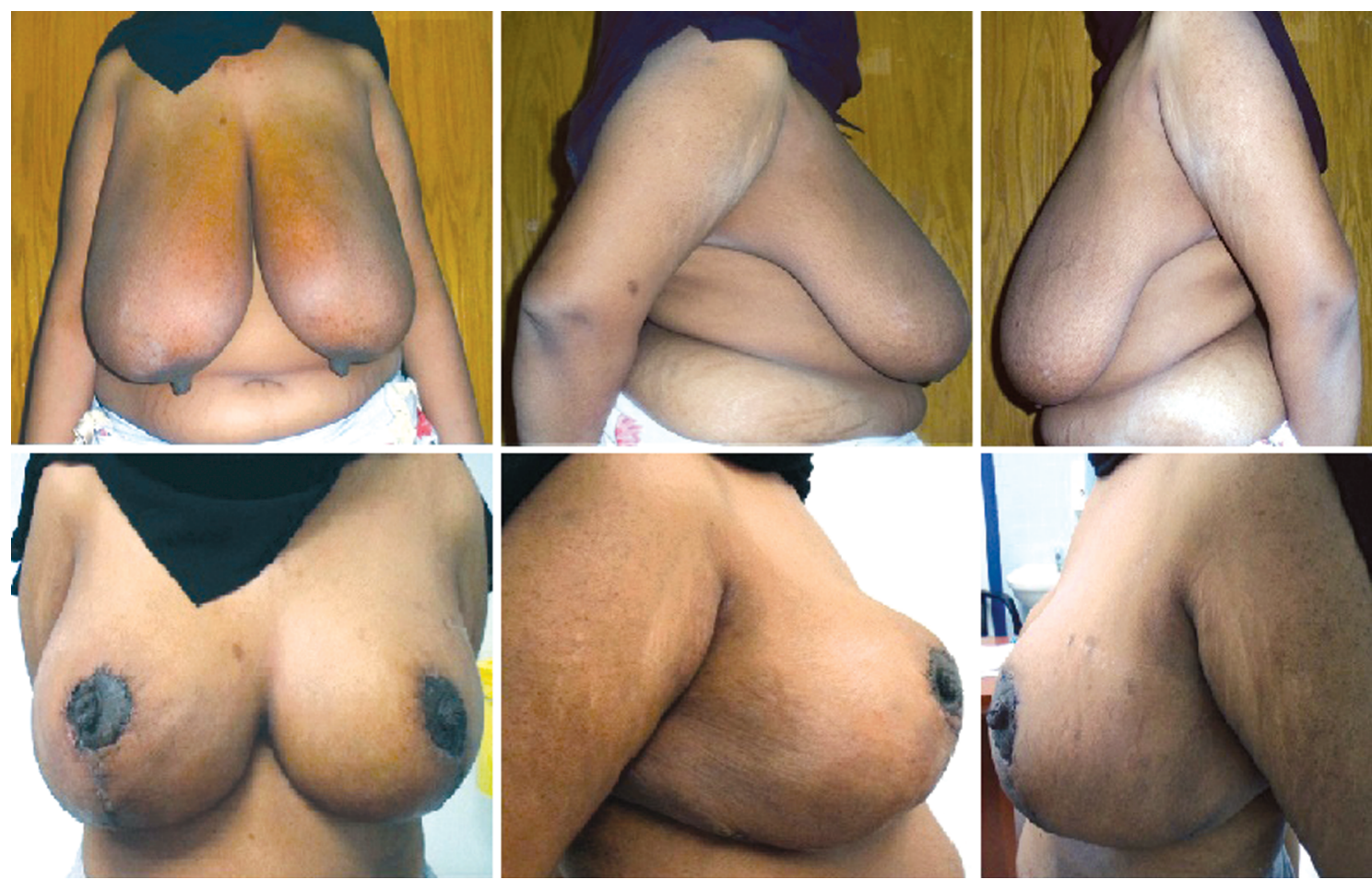

Fig. (5): Reduction mammoplasty. Upper: Preoperative. Lower: Postoperative. 

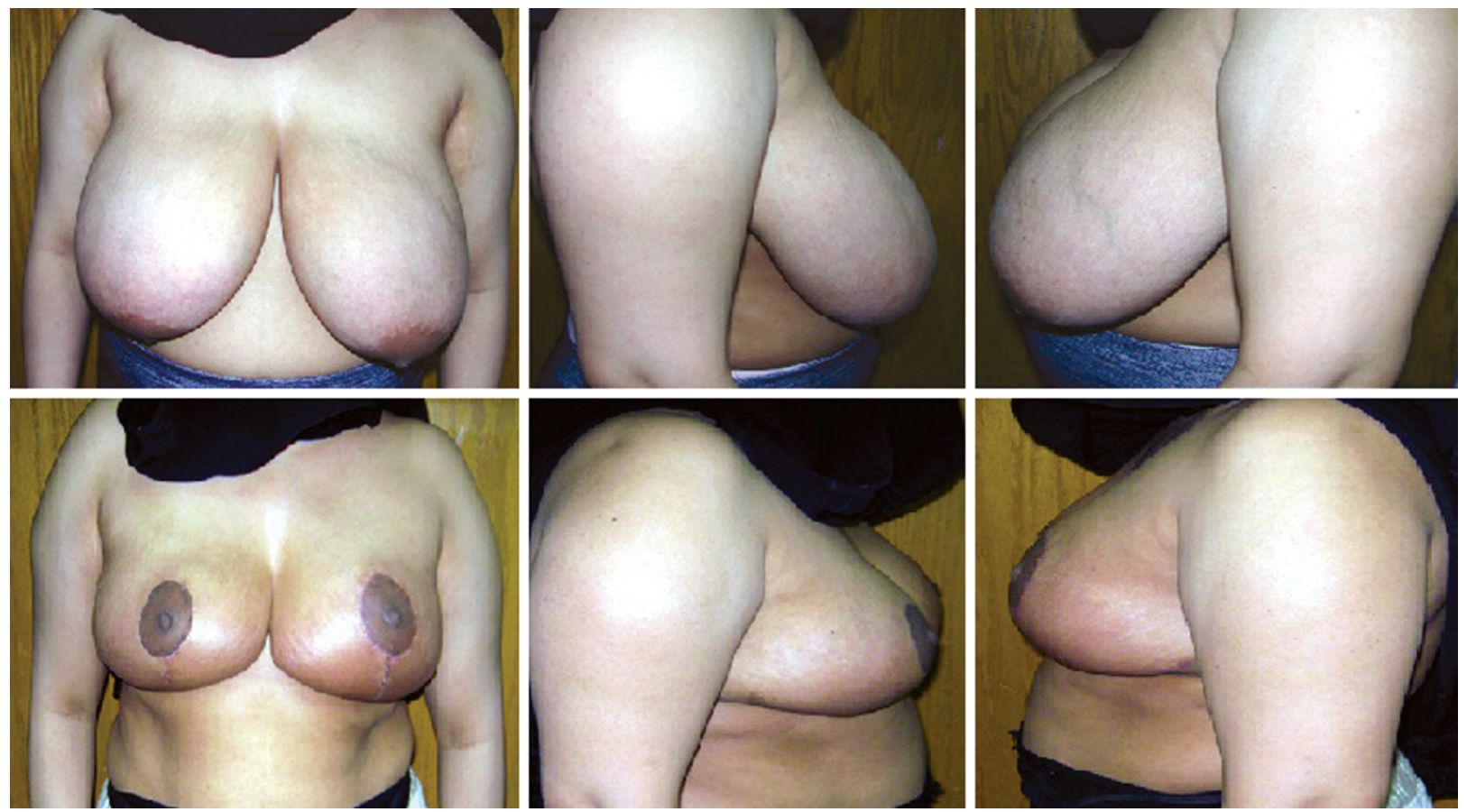

Fig. (6): Reduction mammoplasty. Upper: Preoperative. Lower: Postoperative.
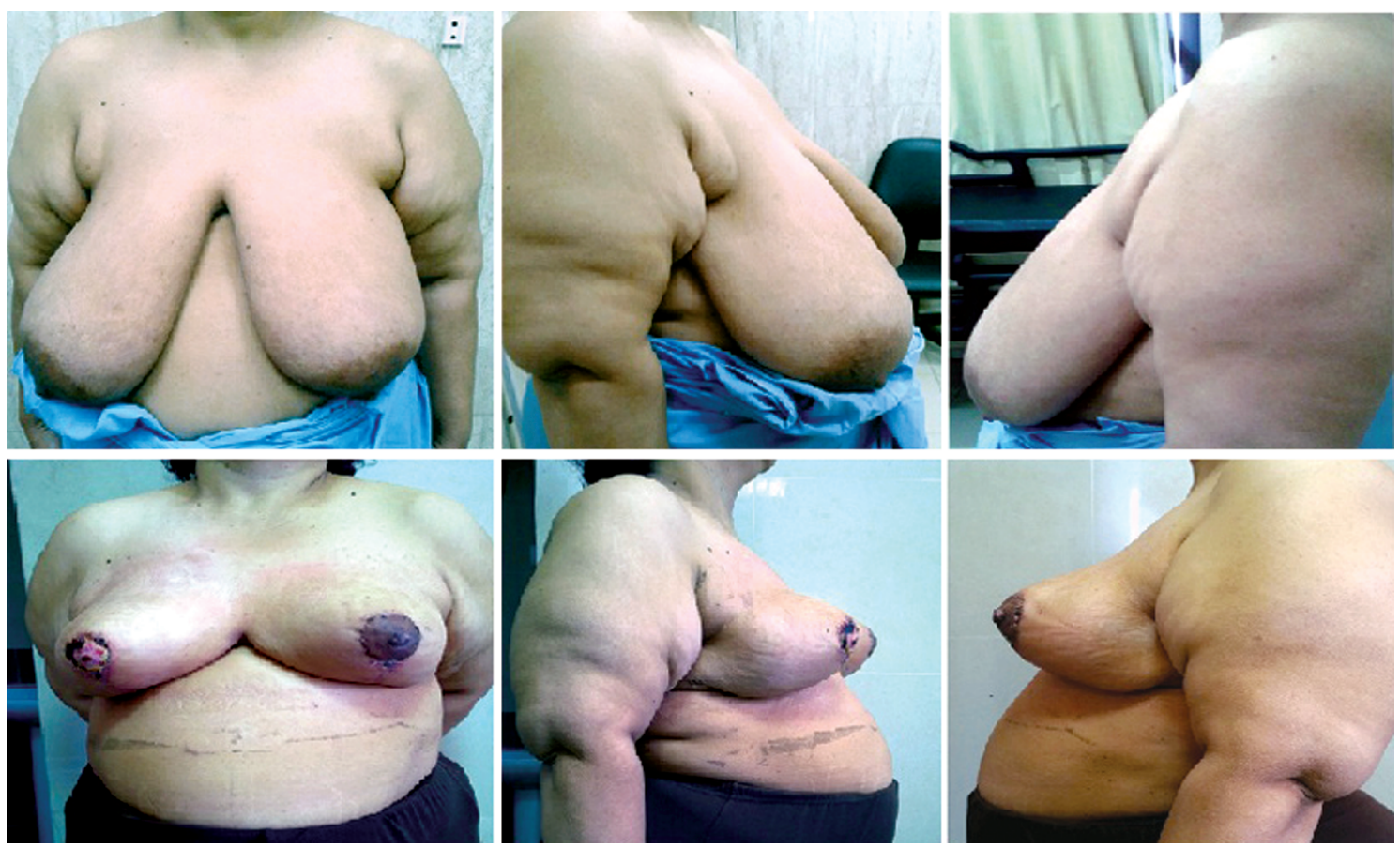

Fig. (7): Reduction mammoplasty with epidermolysis of right nipple areola complex. Upper: Preoperative. Lower: Postoperative. 


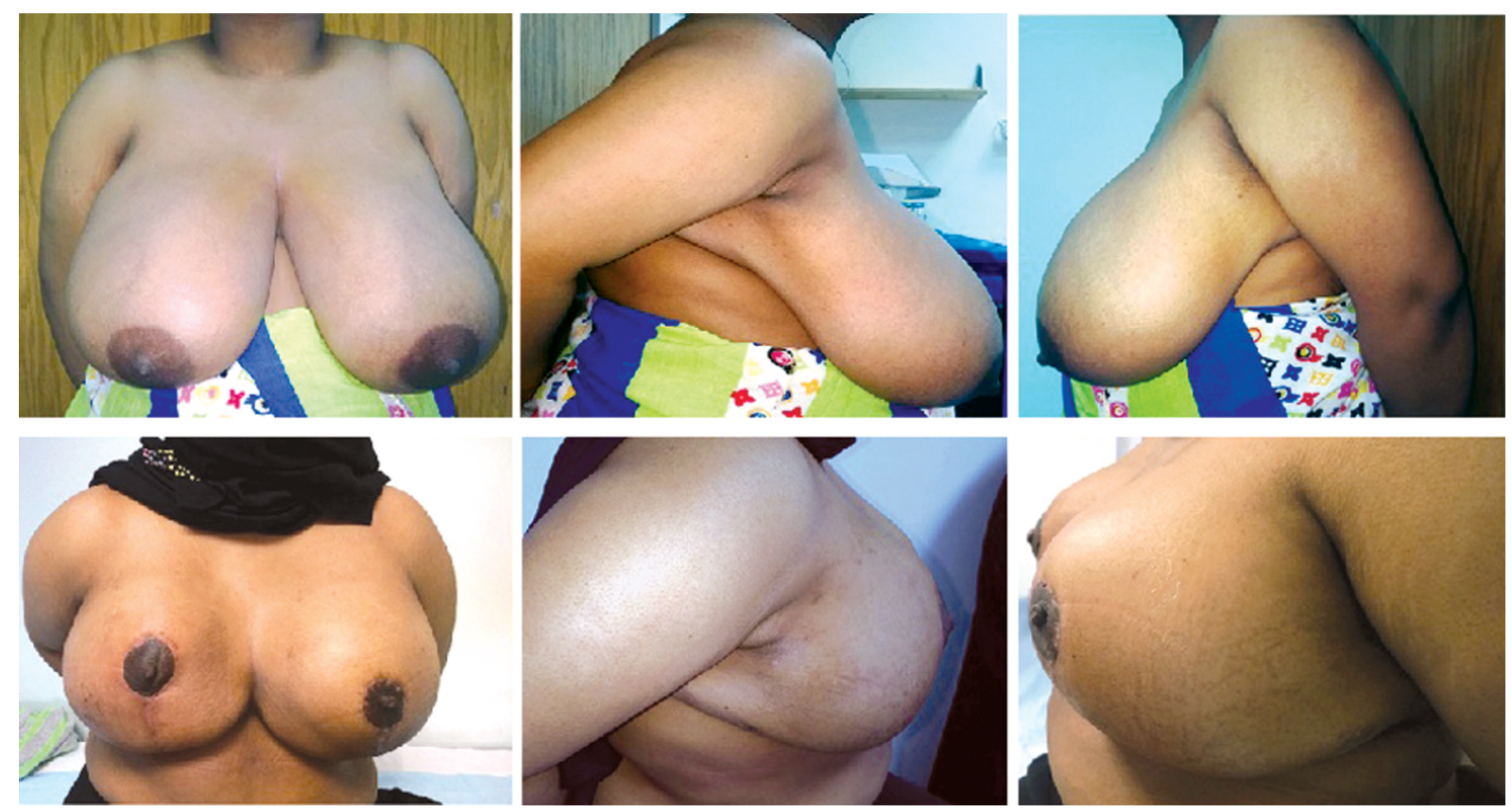

Fig. (8): Reduction mammoplasty with asymmetry between two breasts. Upper: Preoperative. Lower: Postoperative.

\section{DISCUSSION}

Resection of weights ranging from 800-2000 g per breast means that the breast has gigantomastia [30]. In gigantomastia, ptosis is usually severe. The distance from sternal notch-to-nipple is more than $32 \mathrm{~cm} \mathrm{[31].}$

Gigantomastia can be treated by amputation of the breast with free nipple areola graft or inferior pedicle technique. McGregor and Hafeez underwent breast reduction on 22 cases using free nipple grafts. The main drawbacks were scars, and poor return of nipple sensation [32]. No need to say, in younger patients, affection of nipple sensation may lead to litigation [33]. Also, amputation of the breast tissues may lead to flat breasts with loss of upper pole fullness [34-36]. However, free nipple graft still has a place for extremely large $(>2000 \mathrm{~g})$ reductions and severe ptotic breasts where nippleareola complex cannot be preserved.

Inverted ' $\mathrm{T}$ ' breast reductions showed similar complication and re-operation rate if compared with the less extensive vertical reductions. No doubt, the techniques described to limit the amount of scars have rather complicated designs and are probably less easily taught to trainees. In addition, there may be difficulty in folding the pedicle in breasts that have fibrous or glandular breast tissue. Furthermore, it has no safe tracking records for large and ptotic breasts [37].

Regardless indication for breast reduction, Hidalgo conducted a small audience survey of most practiced technique at the 1998 meeting of the American Society of Plastic and Reconstructive Surgeons. From 190 respondents, they concluded that the traditional inferior/central pedicle inverted T-scar method is the most popular procedure [19].

Also, Okoro and his colleagues conducted a survey among 5112 plastic surgeons to identify their preferences and practices and report their opinion regarding issues related to the various breast reduction techniques. They concluded that the inferior pedicle technique has been the preferred procedure and remains so today [38].

A nipple distance of more than $40 \mathrm{~cm}$ from suprasternal notch or lifting of the nipple areola complex (NAC) to $15-20 \mathrm{~cm}$ is an indication for a nipple grafting with a breast reduction [39]. Using vertical reduction mammoplasty, the inframammary distance from the inferior border of areola varies from $5-13 \mathrm{~cm}$ [40]. In Strömbeck technique, the inframammary distance ranges between 6.2-9.5 $\mathrm{cm}$. in this work, the inframammary distance was postoperatively $6 \mathrm{~cm}$ that may reach $7.5 \mathrm{~cm}$ in follow-up (6 months) [41]. It is desirable for this distance to measure 6 to $7 \mathrm{~cm}$ postoperatively as long distance in a small volume breast will appear 'bottomed-out, although a longer distance can be accepted, this relies on the remaining breast tissue [42].

In this series, the medial flap was not undermined to maintain the projection and to prevent hollowness of medial part of breast. The lateral 
flap was undermined extensively to allow easy closure. The pedicle was then tailored in slicing manner from both sides and posterior surface to allow closure of the breast without tension.

In any breast surgery, Symmetry is an essential feature of aesthetic outcome. This was achieved in 19 patients. Asymmetry occurred in two cases presented with extreme huge breasts (2 cases) (Fig. 8 ). Breast asymmetry becomes more noticeable when there is difference in weight (>500 gram) between both breasts. The new nipple-areolar complex (NAC) was made at the dog ear of the vertical limb. This will decrease the length of vertical incision from $10 \mathrm{~cm}$ to $6 \mathrm{~cm}[43,44]$.

In a series of 1192 consecutive patients underwent 2156 reduction mammoplasties', Shermak and his team found a correlation between age and complications. Age older than 50 years increases breast reduction complications particularly infection and impaired wound healing. Hormonal deficiency may partially account for this finding [45].

In this work, age was not more than 45 years and infection rate was very small and confined to skin only. However, third generation cephalosporin's were given for 8 days. No prophylactic antibiotics were given as might irritate normal breast flora [46-49].

Neither seroma nor hematoma was reported as pectoralis fascia was not injured and liposuction was not done. This was fortified by application of drains superficial and deep to the pedicle for three days combined with application of pressure garments for 4 weeks.

Previously, Samadal study with adrenaline infiltration in one breast showed that there was significant decrease in perioperative blood loss with no affection on the viability of skin flaps [50]. This effect of preoperative adrenaline infiltration was evaluated in another study in 24 consecutive patients undergoing breast reduction. A reduction in perioperative blood loss also the mean blood losses in the drains from the infiltrated breasts were significantly less than that from the control sides. These results confirm a beneficial effect of adrenaline on peri and postoperative bleeding [51]. In this study, Tumescent solution was used which resulted in reasonable operative time (3 hours) with no need for blood transfusion.

Hussein emphasized that the low systolic blood pressure in the middle period of the operation which is usually the period of hemostasis is associated with postoperative wound hematoma [52].
In this series, during operation two measures were taken to achieve hemostasis: (1) Elevation of blood pressure by anesthesia team and (2) Irrigation of the wound bed with saline. These maneuvers would detect any bleeding point before closure of wounds.

Abood and Mallucci's advised against the use of drains with excellent outcome and reduced hospital stay [53]. Furthermore, Tam and his team showed relevant results [54]. Drains were used routinely in this series to overcome the rebound effect of adrenaline and guard against any collection. In my opinion, breast reduction is a major surgery with potential wound problems especially for large and ptotic breast that necessities the use of drains as a lifeboat.

All excised tissues were sent for pathological examination. Fortunately, no malignancy was detected. Although uncommon, some authors reported occult breast cancer in the reduction specimen [55, 56]. Actually, sending of breast tissue for pathological examination is a routine for English surgeons and up to $70 \%$ of German surgeons send specimens. This reflects the increased awareness amongst Plastic surgeons on the incidence and identification of breast cancer in bilateral breast reduction cases $[57,58]$.

Two cases showed galactocele on pathological reports and were reassured [59]. They were perimenopausal woman with normal prolactin level. For younger women, more than 1 year was needed after weaning to any patient seeking breast reduction ( 3 cases). This will guard against high prolactin level that may produce multiple breast fistulas through incision sites that may eventually result in complete destruction of breast.

Recently, several authors have reported the complication rate of inferior pedicle reduction. The most common complications are fat necrosis or infection followed by wound dehiscence especially at $\mathrm{T}$ junction [26]. Complications with scar formation at the $\mathrm{T}$-junction have been reported from $12.6 \%$ to $16.8 \%$ of these patients [38,60-62]. Several flaps have been described for this problem such as double skin technique, a glandular dermalsuspension-flap and a protection skin flap in the $\mathrm{T}$ zone $[\mathbf{1 0 , 6 3 , 6 4 ]}$. Using dermal deepithelization was very helpful in our patients for good outcome. It provides good vascularity, less retraction of skin flaps and firm secure bites during suturing especially at the $\mathrm{T}$ shaped junction.

The inverted $\mathrm{T}$ scar is a gathering of three scars: A periareolar scar, a vertical scar, and a submammary scar. Actually, the vertical component fades 
with time and the submammary scar has the most liability to hypertrophy, especially when it extends medially or laterally to the thoracic wall [65]. So, problems with scars were all related to submammary scars, especially the lateral limb. This problem was augmented in patients with dark type of skin (3 cases). Despite this problem, the inframammary fold is still a good place hiding a scar and with time will become almost invisible [66]. Hypertrophic scars were treated with topical corticosteroids and silicone gel [67].

Comparing nipple sensation after superior pedicle technique (18 patients) and nipple sensation after inferior pedicle technique (20 patients), Hamdi found superiority of inferior pedicle technique over vertical reduction using superior pedicle technique [68]. Through a thin horizontal fibrous septum taking origin from the pectoral fascia, vessels and nerves run to the nipple along the level of the fifth rib [69]. So, inferior pedicle has a big number of nerve branches [70]. Our patients experienced good sensation postoperatively except in three patients where sensation was decreased unilaterally in the bigger breast.

\section{Pearls and Pitfalls:}

\section{Before operation:}

Good history taking from the patient is essential especially history of previous operations and family history of breast cancer. Smoking and nonsteroidal anti-inflammatory drugs has to be abounded at least 5 days before operation.

\section{During operation:}

Tumescent solution is infiltrated along incision lines and in breast tissues away from the pedicle. The pedicle is infiltrated at sub epidermal level to facilitate deepithelialization. Deepithelialization of skin flaps for $1 \mathrm{~cm}$ at the edges ensures good bite of sutures, no retraction of skin flaps and eventually good healing of flaps especially at the $\mathrm{T}$ junction site. Blood pressure has to be elevated before closure of wounds to detect any bleeding points and achieve good hemostasis. Drains are placed in front and behind the pedicle to obliterate and decrease tension on the flaps.

\section{Postoperative:}

Garments are applied for four weeks and drains are removed after 3 days.

In summary, any patient with large and ptotic breasts suffered from persistent headache, neck, shoulder or back pain, intertrigo beneath the breasts, deep strap grooves and even urgency in micturition due to pressure on cervical plexus are good candidates for reduction mammoplasty [71,72].

Comparing with other techniques, inferior pedicle has an easy learning curve, good outcome and has one of the safest vascular pedicles to the nippleareola complex, with an excellent record of maintaining nipple sensibility. All breast and skin excess are excised, and the conical shape of breast is achieved at the end of operation. This standard reduction technique is supported by most plastic surgeons with greater satisfaction rates and better versatility than the limited incision methods [73-75].

Some of the disadvantages of this procedure are the long submammary scars, the need for flap undermining laterally, and the risk of bottomingout of the breast over time [76]. In addition, patients after reduction may attain a more normal body appearance.

\section{Conclusion:}

Inferior pedicle technique with some technical refinements was proven to be an excellent and safe technique for breast reduction of large and ptotic breasts. It can give excellent relief of symptoms and good aesthetic results. Patients with large and ptotic breasts are likely to have maximum benefit after inferior pedicle reduction mammoplasty.

\section{Ethical standards:}

This study has been performed in accordance with the ethical standards set forth in the 1964 Declaration of Helsinki and its later amendments. Informed consent was obtained from all parents responsible for participants included in the study.

\section{Disclosure:}

I do not have any financial interests or commercial associations to disclose.

\section{REFERENCES}

1- Losken A., Schaefer T.G., Newell M., et al.: The impact of partial breast reconstruction using reduction techniques on postoperative cancer surveillance. Plast. Reconstr. Surg., 124: 9-17, 2009.

2- Losken A., Styblo T.M., Carlson G.W., et al.: Management algorithm and outcome evaluation of partial mastectomy defects treated using reduction or mastopexy techniques. Ann. Plast. Surg., 59: 235-42, 2007.

3- Kronowitz S.J., Hunt K.K., Kuerer H.M., et al.: Practical guidelines for repair of partial mastectomy defects using the breast reduction technique in patients undergoing breast conservation therapy. Plast. Reconstr. Surg., 120: 1755-1768, 2007. 
4- Losken A., Elwood E.T., Styblo T.M., et al.: The role of reduction mammaplasty in reconstructing partial mastectomy defects. Plast. Reconstr. Surg., 109: 968-975, 2002.

5- Shestak K.C., Johnson R.R., Greco R.J., et al.: Partial mastectomy and breast reduction as a valuable treatment option for patients with macromastia and carcinoma of the breast. Surg. Gynecol. Obstet., 177: 54-56, 1993.

6- Newman L.A., Kuerer H.M., McNeese M.D., et al.: Reduction mammoplasty improves breast conservation therapy in patients with macromastia. Am. J. Surg., 181: 215$220,2001$.

7- Spear S.L., Pelletiere C.V., Wolfe A.J., et al.: Experience with reduction mammaplasty combined with breast conservation therapy in the treatment of breast cancer. Plast. Reconstr. Surg., 111: 1102-1109, 2003.

8- Jones J.A. and Pu L.L.: Oncoplastic approach to early breast cancer in women with macromastia. Ann. Plast. Surg., 58: 34-38, 2007.

9- Skoog T.: A technique of breast reduction; transposition of the nipple on a cutaneous vascular pedicle. Acta. Chir. Scand, 126: 453-65, 1963.

10- McKissok P.K.: Reduction mammaplasty with vertical dermal flap. Plast. Reconstr. Surg., 49: 245-52, 1972.

11- Robbins T.H.: A reduction mammaplasty with the areolanipple based on an inferior dermal pedicle. Plast. Reconstr. Surg., 59: 64-67, 1977.

12- Durston W.: Concerning a very sudden and excessive swelling of a women's breasts. Phil Trans, Vol. IV, for Anno 1669, 1047-1049. London: Royal Society, 1670.

13- Andrades P. and Prado A.: Understanding modern breast reduction techniques with a simplified approach. J. Plast. Reconstr. Aesthet. Surg., 61 (11): 1284-93, 2008.

14- Deaver J.B. and McFarland J.: The breast: Its anomalies, its diseases and their treatment. Philadelphia: Blakiston, 1917.

15- McCulley S.J. and Rousseau T.E.: A modified Chiari L short scar mammaplasty the technique and results. Br. J. Plast. Surg., 52: 112-7, 1999.

16- Adams W.M.: Free transplantation of the nipples and areolae. Surgery, 15: 186-95, 1944.

17- Farina R. and Villano J.B.: Reduction mammaplasty with free grafting of the nipple and areola. Br. J. Plast. Surg., 25: 393-398, 1972.

18- Oneal R.M., Goldstein J.A., Rohrich R., Izenberg P.H. and Pollock R.A.: Reduction mammaplasty with free nipple transplantation: Indications and technical refinements. Ann. Plast. Surg., 26: 117-121, 1991.

19- Hidalgo D.A., Elliot L.F., Palumbo S., et al.: Current trends in breast reduction. Plast. Reconstr. Surg., 104: 806-815; quiz 816; discussion, 817-808, 1999.

20- Blomqvist L., Eriksson A. and Brandberg Y.: Reduction mammaplasty provides long-term improvement in health status and quality of life. Plast. Reconstr. Surg., 106: 991997, 2000.

21- Gonzalez F., Walton R.L., Shafer B., et al.: Reduction mammaplasty improves symptoms of macromastia. Plast. Reconstr. Surg., 91: 1270-1276, 1993.
22- Miller B.J., Morris S.F., Sigurdson L.L., et al.: Prospective study of outcomes after reduction mammaplasty. Plast. Reconstr. Surg., 115: 1025-1031; discussion 1032-1033, 2005.

23- Menderes A., Mola F., Vayvada H., et al.: Evaluation of results from reduction mammaplasty: Relief of symptoms and patient satisfaction. Aesthetic Plast. Surg., 29: 8387, 2005.

24- Woodman R. and Radzyminski S.: Women's perception of life following breast reduction: A phenomenological study. Plast. Surg. Nurs., 27: 85-92, 2007.

25- Faria F.S., Guthrie E., Bradbury E., et al.: Psychosocial outcome and patient satisfaction following breast reduction surgery. Br. J. Plast. Surg., 52: 448-452, 1999.

26- Egmont D.B., Isselstein K.I. and Ramselaar J.M.: A comparison between two methods of reduction mammaplasty. Eur. J. Plast. Surg., 15: 75-78, 1992.

27- Davis G.M., Ringler S.L., Short K., Sherrik D. and Bengtson B.P.: Reduction mammaplasty: Long term efficacy, morbidity, and patient satisfaction. Plast. Reconstr. Surg., 96 (5): 1106-1110, 1995.

28- Dabbah A., Lehman J.A., Parker M.G., Tantri D. and Wagner D.: Reduction mammaplasty: An outcome analysis. Ann. Plast. Surg., 35: 337-341, 1995.

29- Giovanoli P., Meuli-Simmen C., Meyer V.E. and Frey M.: Which technique for which breast? A prospective study of different techniques of reduction mammaplasty. Br. J. Plast. Surg., 52: 52-59, 1999.

30- Dancey A., Khan M., Dawson J., et al.: Gigantomastiaea classification and review of the literature. J. Plast. Reconstr. Aesthet Surg., 61: 493-502, 2008.

31- Jackson I.T., Bayramicli M., Gupta M. and Yavuzer R.: Importance of the pedicle length measurement in reduction mammaplasty. Plast. Reconstr. Surg., 104: 398-400, 1999.

32- McGregor J.C1 and Hafeez A.: Is there still a place for free nipple areolar grafting in breast reduction surgery? A review of cases over a three year period. J. Plast. Reconstr. Aesthet. Surg., 59 (3): 213-8; discussion 219220, 2006.

33- Hoffman S.: Reduction mammaplasty: A medico-legal hazard? Aesthetic Plast. Surg., 11: 113-116, 1987.

34- Chang P., Shaaban A.F., Canady J.W., et al.: Reduction mammaplasty: The results of avoiding nipple-areolar amputation in cases of extreme hypertrophy. Ann. Plast. Surg., 37: 585-591, 1996.

35- Gerzenshtein J., Oswald T., McCluskey P., et al.: Avoiding free nipple grafting with the inferior pedicle technique. Ann. Plast. Surg., 55: 245-249, 2005.

36- Lacerna M., Spears J., Mitra A., et al.: Avoiding free nipple grafts during reduction mammaplasty in patients with gigantomastia. Ann. Plast. Surg., 55: 21-24. discussion 24, 2005.

37- Beer G.M., Spicher I., Cierpka K.A. and Meyer V.E.: Benefits and pitfalls of vertical scar breast reduction. Br. J. Plast. Surg., 57: 12-19, 2004.

38- Okoro S.A., Barone C., Bohnenblust M. and Wang H.T.: Breast reduction trend among plastic surgeons: A national survey. Plast. Reconstr. Surg. Nov., 122 (5): 1312-20, 2008. 
39- Pickford M.A. and Boorman J.G.: Early experience with the Lejour vertical scar reduction mammaplasty technique. Br. J. Plast. Surg., 46: 516-22, 1993.

40- Berg A., Palmer B. and Stark B.: Early experience with Lejour vertical scar reduction mammaplasty technique. Eur. J. Plast. Surg., 18: 214-18, 1995.

41- Strömbeck J.O.: Macromastia in women and its surgical treatment: A clinical study based on 1042 cases. Acta. Chir. Scand, Suppl. (341): 1-128, 1964.

42- Beer G.M1, Morgenthaler W., Spicher I. and Meyer V.E.: Modifications in vertical scar breast reduction. Br. J. Plast. Surg. Jun., 54 (4): 341-347, 2001.

43- Hughes L.A. and Mahoney J.L.: Patient satisfaction with reduction mammaplasty: An early survey. Aesth. Plast. Surg., 17: 345-349, 1993.

44- Lejour M.: Vertical mammaplasty and liposuction of the breast. Plast. Reconstr. Surg., 94: 100-114, 1994.

45- Shermak M.A., Chang D., Buretta K., Mithani S., Mallalieu J. and Manahan M.: Increasing age impairs outcomes in breast reduction surgery. Plast. Reconstr. Surg., 128 (6): 1182-7, 2011

46- Serletti J.M., Davenport M.S., Herrera H.R., et al.: Efficacy of prophylactic antibiotics in reduction mammoplasty. Ann. Plast. Surg., 33: 476, 1994.

47- Ahmadi A.H., Cohen B.E., Shayani P.: A prospective study of antibiotic efficacy in preventing infection in reduction mammaplasty. Plast. Reconstr. Surg., 116: 126, 2005.

48- O'Grady K.F., Thoma A. and Dal Cin A.: A comparison of complication rates in large and small inferior pedicle reduction mammaplasty. Plast. Reconstr. Surg., 115: 736, 2005.

49- Ransjo U., Asplund O., Gilbert L., et al.: Bacteria in the female breast. Scand J. Plast. Reconstr. Surg., 19: 87, 1985.

50- Samdal F., Serra M. and Skolleborg K.C.: The effects of infiltration with adrenaline on blood loss during reduction mammaplasty. Scand J. Plast. Reconstr. Hand Surg., 26: 211-215, 1992.

51- Metaxotos N.G., Asplund O. and Hayes M.: The efficacy of bupivacaine with adrenaline in reducing pain and bleeding associated with breast reduction: A prospective trial. Br. J. Plast. Surg. Jun., 52 (4): 290-293, 1999.

52- Hussien M., Lee S., Malyon A., Norrie J. and Webster M.: The impact of intraoperative hypotension on the development of wound haematoma after breast reduction. Br. J. Plast. Surg. Sep., 54 (6): 517-22, 2001.

53- Abood A. and Mallucci P.: In response to: Collis N., McGuiness C.M., Batchelor A.G. Drainage in breast reduction surgery: A prospective randomised intra-patient trial. Br. J. Plast. Surg., 58: 286e9, 2005. J. Plast. Reconstr. Aesthet. Surg., 59: 433, 2006.

54- Tan J., Timmons M.J. and Watt D.A.: Breast reduction surgery without drains. J. Plast. Reconstr. Aesthet. Surg., 60 (10): 1168-9. Epub 2007 Aug 10, 2007.

55- Brown M.H., Weinberg M., Chong N., Levine R. and Holowaty E.: A cohort study of breast cancer risk in breast reduction patients. Plast Reconstr Surg., 103: 1674-1681, 1999.
56- Colwell A.S., Kukreja J., Breuing K.H., Lester S. and Orgill D.P.: Occult breast carcinoma in reduction mammaplasty specimens: 14-year experience. Plast. Reconstr. Surg., 113: 1984-1988, 2004.

57- Hage J.J. and Karim R.B.: Risk of breast cancer among reduction mammaplasty patients and the strategies used by plastic surgeons to detect such cancer. Plast. Reconstr. Surg., 117: 727-735, 2006.

58- Titley O.G., Armstrong A.P., Christie J.L., et al.: Pathological findings in breast reduction surgery. Br. J. Plast. Surg., 49: 447-451, 1996.

59- Bentley M1, Ghali S. and Asplund O.A.: Galactorrhoea causing severe skin breakdown and nipple necrosis following breast reduction. Br. J. Plast. Surg. Oct., 57 (7): 682-684, 2004.

60- Rorich R., Gosma A.A., Brown S.A., Tonadapu P. and Foster B.: Current preferences for breast reduction techniques: A survey of board-certified plastic surgeons 2002. Plast. Reconstr. Surg., 114 (7): 1724-1733, 2004.

61- Stevens W.G., Gear A.J., Stoker D.A., et al.: Outpatient reduction mammaplasty: An eleven-year experience. Aesthet. Surg. J., 28 (2): 171-179, 2008.

62- Goes J.C.: Periareolar mammaplasty with mixed mesh support: The double skin technique. Plast. Reconstr. Surg., 97 (5): 959-968, 1996.

63- Exner K. and Scheufler O.: Dermal suspension flap in vertical-scar reduction mammaplasty. Plast. Reconstr. Surg., 109 (7): 2289-2298, 2002.

64- Mateucci P. and fourie le R.: Skin sparing mastectomy using the Wise pattern: Protecting the T junction with a dermal pedicle. Br. J. Plast. Surg., 57 (5): 473-475, 2004.

65- Wallace W.H., Thompson W.O.B., Smith R.A., Barraza K.R., Davidson S.F. and Thompson J.T.: Reduction mammaplasty using the inferior pedicle technique. Ann. Plast. Surg., 40: 235, 1998.

66- Corduff N. and Taylor G.I.: Subglandular breast reduction: The evolution of a minimal scar approach to breast reduction. Plast. Reconstr. Surg. Jan., 113 (1): 175-184, 2004.

67- Dex E.A1, Asplund O., Ardehali B. and Eccles S.J.: A method to select patients for vertical scar or inverted-T pattern breast reduction. J. Plast. Reconstr. Aesthet. Surg. Nov., 61 (11): 1294-302, 2008.

68- Hamdi M., Greuse M., De Mey A. and Webster M.H.: A prospective quantitative comparison of breast sensation after superior and inferior pedicle mammaplasty. Br. J. Plast. Surg. Jan., 54 (1): 39-42, 2001.

69- Sarhadi N.S., Shaw Dunn J., Lee F.D., Soutar D.S.: An anatomical study of the nerve supply of the breast, including the nipple and areola. Br. J. Plast. Surg., 49: 156-64, 1996.

70- Jaspars J.J.P., Posma A.N., van Immerseel A.A.H. and Gittenberger-de Groot A.C.: The cutaneous innervation of the female breast and nipple-areola complex: Implications for surgery. Br. J. Plast. Surg., 50: 249-59, 1997.

71- Miller A.P., Zacher J.B., Berggren R.B., Falcone R.E. and Monk J.: Breast reduction for symptomatic macromastia: Can objective predictors for operative success be identified? Plast. Reconstr. Surg., 95: 77-83, 1995. 
72- Hollyman J.A., Lacey J.H. \& Whitfield P.J.: Surgery for the psyche: A longitudinal study of women undergoing reduction mammaplasty. Br. J. Plast. Surg., 39: 22-24, 1986.

73- Menke H., Eisenmann-Klein M., Olbrisch R.R. and Exner K.: Continuous quality management of breast hypertrophy by the German Association of Plastic Surgeons: A preliminary report. Ann. Plast. Surg., 46: 594, 2001.

74- Zubowski R., Zins J.E., Foray-Kaplon A., et al.: Relation- ship of obesity and specimen weight to complications in reduction mammaplasty. Plast. Reconstr. Surg., 106: 998, 2000.

75- Economides N.G. and Sifakis F.: Reduction mammaplasty: A study of sequelae. Breast J., 3: 69, 1997.

76- Nahai F.R1 and Nahai F.: MOC-PSSM CME article: Breast reduction. Plast. Reconstr. Surg., 121 (1 Suppl): 1-13: 10, 2008. 